\title{
Effects of Image Gently and the North American Guidelines: Administered Activities in Children at 13 North American Pediatric Hospitals
}

\author{
Frederic H. Fahey ${ }^{1}$, Sonja I. Ziniel ${ }^{2-4}$, Dacie Manion ${ }^{5}$, and S. Ted Treves ${ }^{1}$ \\ ${ }^{I}$ Division of Nuclear Medicine and Molecular Imaging, Department of Radiology, Boston Children's Hospital, Harvard Medical \\ School, Boston, Massachusetts; ${ }^{2}$ Center for Patient Safety and Quality Research, Program for Patient Safety and Quality, Boston \\ Children's Hospital, Harvard Medical School, Boston, Massachusetts; ${ }^{3}$ Division of Adolescent and Young Adult Medicine, Boston \\ Children's Hospital, Harvard Medical School, Boston, Massachusetts; ${ }^{4}$ Department of Pediatrics, Harvard Medical School, \\ Boston, Massachusetts; and ${ }^{5}$ Massachusetts Institute of Technology, Cambridge, Massachusetts
}

The goal of this investigation was to assess the impact of the publication of the 2010 North American guidelines on the practice of nuclear medicine in children at 13 dedicated pediatric institutions within the United States and Canada by comparing results of similar surveys from 2007 and 2013. Methods: In 2013, a follow-up survey was performed of the original 13 dedicated pediatric institutions initially surveyed in 2007 . Both surveys inquired about the administered activities for 16 nuclear medicine procedures commonly performed on children. The administered activity per body mass, the maximum activity, and the minimum activity for patients for each procedure were requested from each site. For each parameter the minimum and maximum reported values, as well as the median and the mean, were tabulated. The mean difference in the mean between 2007 and 2013 was calculated, as well as the $95 \%$ confidence intervals for the mean administered activity per body mass for both years. The factor of variation used with the previous survey for each parameter was calculated by taking the ratio of the maximum and minimum reported values. For the 8 procedures addressed in the 2010 North American guidelines, the percentage of institutions that were compliant (defined as within 20\%) for each parameter were noted for both surveys. Institutions were asked whether they were familiar with "Image Gently," the North American guidelines, and the "Go with the Guidelines" campaign and whether they adjusted their administered activities on the basis of these guidelines. Results: In general, the 13 pediatric institutions have reduced their administered activities in children, particularly for those procedures addressed by the 2010 North American guidelines. The average variability in the activity per body mass and the minimum activity as measured by the factor of variation were substantially reduced by $9.7 \%$ (from 3.1 to 2.8 ) and $24 \%$ (from 10.0 to 7.6 ). The average variability of the maximum activity was increased by $6.1 \%$ (from 3.3 to 3.5 ), but the increase was mostly due to some sites reducing their limits while others maintained their previous values. For the 8 procedures addressed by the guidelines, half or more of the institutions were compliant (within 20\%) with the associated parameters in $66 \%$ of the cases. Ten of the 13 institutions reported that they adjusted their administered activities according to the North American guidelines. Conclusion: The publication of these guidelines

Received Sep. 19, 2014; revision accepted Apr. 10, 2015.

For correspondence or reprints contact: Frederic H. Fahey, Division of Nuclear Medicine, Boston Children's Hospital, 300 Longwood Ave., Boston, MA 02115.

E-mail: frederic.fahey@childrens.harvard.edu

Published online Apr. 30, 2015.

COPYRIGHT (C) 2015 by the Society of Nuclear Medicine and Molecular Imaging, Inc. and the associated public relations program appear to have had a positive effect with regard to both dose optimization and procedure standardization in pediatric nuclear medicine.

Key Words: pediatric radiopharmaceutical dosing; children; North American guidelines; Image Gently; pediatric nuclear medicine

J Nucl Med 2015; 56:962-967

DOI: 10.2967/jnumed.114.148767

$\mathbf{T}$ he clinical value of nuclear medicine for several pediatric disorders has been well established across many medical specialties, including urology, neurology, orthopedics, and oncology (1). However, nuclear medicine requires the administration of radioactivity to the patient and thus exposure to ionizing radiation. Although controversies exist, there may be a small, potential risk even from the low levels of ionizing radiation exposure experienced in clinical nuclear medicine (2). In addition, children are considered to be at higher risk for radiation-induced cancer than adults (3). Therefore, it is prudent to consider the optimum administered activity for pediatric nuclear medicine to be a patient size-related function that keeps the radiation dose to the patient as low as possible while continuing to provide the diagnostic information necessary for proper care.

In 2007, we performed a survey of 13 North American pediatric institutions concerning the approaches used to determine the administered activities for smaller patients, as well as the actual activity levels (4). That survey demonstrated a wide variation in administered activities, even among the most respected pediatric institutions in North America. The administered activity per unit of body mass and the maximum administered activity varied on average by a factor of 3 across institutions. The minimum administered activity below which an adequate study cannot be acquired varied on average by a factor of 10 and by as much as a factor of 20 in one case.

This survey, along with a growing interest in dose optimization within pediatric radiology among the media, government agencies, and the public, led to the "Image Gently" campaign, which seeks to raise awareness of the opportunities to lower radiation dose in the imaging of children (5). Also, the American College of Radiology, the Society of Pediatric Radiology, and the Society of Nuclear Medicine and Molecular Imaging (SNMMI) convened 
a working group for pediatric nuclear medicine that resulted in the development and the publication of the North American consensus guidelines for administered activity in children and adolescents (6). A public relations campaign was launched ("Go with the Guidelines") that sought to deliver a copy of the guidelines to every nuclear medicine clinic in North America by its publication in multiple journals and insertion into the radiopharmaceutical packages delivered to the clinics. By performing a follow-up to our 2007 survey of the same 13 pediatric institutions, we sought to determine whether the combination of the publication of the initial survey, the North American consensus guidelines, and the "Go with the Guidelines" poster has had a positive effect on the standardization of administered activities in pediatric nuclear medicine.

\section{MATERIALS AND METHODS}

Since this study involved the survey of nuclear medicine practice rather than data from individual patients, it did not require approval by the Institutional Review Board at Boston Children's Hospital. A survey similar to the 2007 survey was administered to the same 13 pediatric institutions. The same 16 procedures commonly performed in pediatric nuclear medicine were considered in the follow-up survey. Boston Children's Hospital, our home institution, was included in this followup survey because it was included in the previous survey. For each procedure, we asked about the approach used to determine the amount of administered activity as a function of patient size as well as the maximum (in large patients) and minimum (in very small patients) administered activities. If the site indicated that administered activity had been scaled by patient body mass, the administered activity per kilogram was also requested. The survey also asked 3 questions to assess the effectiveness of the "Image Gently" campaign: was the site familiar with the campaign or with the 2010 North American consensus guidelines, and did the site modify any of its protocols as a result of the publication of the North American consensus guidelines. The questionnaire used for the follow-up survey is shown in Supplemental Figure 1 (supplemental materials are available at http://jnm.snmjournals.org).

For the 2013 survey, descriptive statistics (minimum, maximum, mean, and median) are reported for the following parameters: the minimum and maximum administered activities (in $\mathrm{MBq}$ in the article tables and $\mathrm{mCi}$ in the supplemental tables) and the administered activity per unit of body mass (in $\mathrm{MBq} / \mathrm{kg}$ in the article tables and $\mathrm{mCi} / \mathrm{kg}$ in the supplemental tables). Differences between the 2013 and 2007 reported values were calculated for each institution, procedure, and parameter of administered activity. The mean of these differences across institutions was reported. The 95\% confidence intervals of the mean for each parameter are also presented for 2007 and 2013. In addition, for each parameter reported, the value from the institution reporting the highest (maximum) value divided by the value from the institution reporting the lowest (minimum) value was considered the "factor of variation." This factor of variation was also used as a parameter of variability in the reporting of the 2007 survey. The factors of variation for 2007 and 2013 were compared to assess whether the variability had changed since the first survey. The percentage of institutions reporting dose schedules for a particular procedure consistent with the North American guidelines was tabulated. For the purposes of this report, a window of $\pm 20 \%$ was used to establish consistency following the variance allowed by the U.S. Nuclear Regulatory Commission for the administered activity for diagnostic use to a particular patient to comply with the prescribed value (7).

\section{RESULTS}

All 13 institutions that responded to the 2007 survey participated in this follow-up survey. Table 1 presents the summary data with minimum and maximum reported values, as well as the median and mean, for each parameter of administered activity. The values are reported in
$\mathrm{MBq}$ and $\mathrm{MBq} / \mathrm{kg}$. An alternative version of the table in conventional units $(\mathrm{mCi}$ and $\mathrm{mCi} / \mathrm{kg}$ ) is provided online (Supplemental Table 1). The mean differences between the parameters reported in 2007 and 2013, the factors of variation for 2013, and the $95 \%$ confidence intervals of the means from the 2 surveys are shown in Table 2 (conventional units in Supplemental Table 2). Many of the average parameter maximums did not show any change, as indicated by a mean difference of $0(37.5 \% ; 18 / 48)$. Overall, most changes were in the average parameter minimums and means. Most changes observed for both statistics were decreases in the activity parameters between 2007 and 2013: $87.5 \%$ (42/48) of the mean differences regarding the minimum and $72.9 \%(35 / 48)$ of the mean differences regarding the mean showed negative values. For 7 of the 16 procedures, the mean of the mean differences across the institutions of at least 1 of its 3 parameters was positive. However, none of these 7 procedures were included in the 2010 North American consensus guidelines and thus no guidance was provided for a more appropriate value.

For the activity per unit body mass, the average factor of variation across the 16 protocols was reduced by $9.7 \%$ from 3.1 in 2007 to 2.8 in 2013 . The factor of variation increased for 4 of the 16 protocols, but in all those cases the change represented an overall reduction in administered activity rather than an increase. For the maximum activity parameter, the average factor of variation increased by $6.1 \%$ from 3.3 to 3.5 for 2007 and 2013, respectively. The factor increased in 7 of the 16 protocols. In 2 cases ( ${ }^{99 \mathrm{~m}} \mathrm{Tc}$-labeled denatured red blood cells for splenic imaging and ${ }^{67} \mathrm{Ga}$ for imaging inflammation), this change indicated an increase in the administered activity. Neither of these protocols was addressed by the North American guidelines. A 24\% reduction in the factor of variation from 10.0 in 2007 to 7.6 in 2013 was observed for the average minimum activity parameter. For only 1 protocol $\left({ }^{99 \mathrm{~m}} \mathrm{Tc}-\right.$ mercaptoacetyltriglycine renal imaging) did the factor of variation increase, and this change represented an overall decrease in the minimum administered activity.

Table 3 presents the percentage of institutions whose reported activity amounts, minimums, and maximums were compliant (within 20\%) for 8 procedures described in the North American consensus guidelines, that is, ${ }^{18} \mathrm{~F}$-FDG PET, ${ }^{99 \mathrm{~m} T c}$-methylene diphosphate bone scans, ${ }^{123}$ I-metaiodobenzylguanidine, ${ }^{99 \mathrm{~m}} \mathrm{Tc}$-labeled hepatobiliary agents, ${ }^{99 \mathrm{~m}} \mathrm{Tc}$-dimercaptosuccinic acid renal cortical scans, ${ }^{99 \mathrm{~m}} \mathrm{Tc}-$ $\mathrm{TcO}_{4}$ for $\mathrm{Meckel}$ diverticulum, ${ }^{99 \mathrm{~m}} \mathrm{Tc}$-mercaptoacetyltriglycine renal scans, and ${ }^{99 \mathrm{~m}} \mathrm{Tc}-$ macroaggregated albumin for lung scans (6). The percentage of institutions following the guidelines increased between the 2007 and 2013 surveys for 7 of these 8 procedures. The compliance also increased for the minimum administered activity for all 8 procedures and increased or remained stable for the 2 procedures with guidelines for maximum administered activities. Across all 18 parameters covered by the guidelines, 66.7\% (12/18) showed more than $50 \%$ of the institutions in compliance. All 13 institutions were familiar with "Image Gently" and the 2010 North American guidelines. Ten of the 13 indicated that they adjusted their administered activities on the basis of the North American guidelines.

\section{DISCUSSION}

Traditionally, the practice of nuclear medicine has tended to be less standardized in pediatric patients than in adults. In contrast, numerous technical practice guidelines for adult nuclear medicine have been developed and are updated regularly by various professional associations such as SNMMI, the American College of Radiology, and the European Association of Nuclear Medicine 
TABLE 1

Summary of Survey Data

\begin{tabular}{|c|c|c|c|c|c|c|}
\hline Radiopharmaceutical & Parameter & $\begin{array}{l}\text { No. of } \\
\text { respondents }\end{array}$ & Minimum & Maximum & Median & Mean \\
\hline \multirow[t]{3}{*}{ 99mTc-dimercaptosuccinic acid } & Activity/mass (MBq/kg) & 12 & 1.22 & 2.78 & 1.85 & 1.91 \\
\hline & Minimum activity (MBq) & 13 & 5.55 & 49.95 & 18.50 & 21.35 \\
\hline & Maximum activity (MBq) & 11 & 74.00 & 185.00 & 111.00 & 124.46 \\
\hline \multirow[t]{3}{*}{${ }^{99 m}$ Tc-mercaptoacetyltriglycine } & Activity/mass (MBq/kg) & 10 & 1.11 & 5.55 & 3.70 & 3.55 \\
\hline & Minimum activity (MBq) & 12 & 18.13 & 148.00 & 37.00 & 47.76 \\
\hline & Maximum activity (MBq) & 12 & 55.50 & 370.00 & 148.00 & 180.38 \\
\hline \multirow[t]{3}{*}{ 99mTc-methylene diphosphate } & Activity/mass (MBq/kg) & 11 & 7.40 & 9.25 & 9.25 & 8.95 \\
\hline & Minimum activity (MBq) & 12 & 37.00 & 111.00 & 55.50 & 65.37 \\
\hline & Maximum activity (MBq) & 11 & 555.00 & 925.00 & 740.00 & 746.73 \\
\hline \multirow[t]{3}{*}{ 99mTc-diisopropyl iminodiacetic acid } & Activity/mass (MBq/kg) & 10 & 0.74 & 2.78 & 1.85 & 1.91 \\
\hline & Minimum activity (MBq) & 13 & 14.80 & 74.00 & 37.00 & 31.91 \\
\hline & Maximum activity (MBq) & 12 & 51.80 & 259.00 & 185.00 & 167.73 \\
\hline \multirow[t]{3}{*}{ 123|-metaiodobenzylguanidine } & Activity/mass (MBq/kg) & 12 & 4.44 & 7.40 & 5.18 & 5.55 \\
\hline & Minimum activity (MBq) & 12 & 37.00 & 111.00 & 37.00 & 51.43 \\
\hline & Maximum activity (MBq) & 13 & 296.00 & 370.00 & 370.00 & 360.04 \\
\hline \multirow[t]{3}{*}{ 99mTc-NaTcO 4 (Meckel diverticulum) } & Activity/mass (MBq/kg) & 11 & 1.63 & 3.70 & 1.85 & 2.57 \\
\hline & Minimum activity (MBq) & 13 & 7.40 & 111.00 & 18.50 & 34.01 \\
\hline & Maximum activity (MBq) & 11 & 111.00 & 740.00 & 370.00 & 336.36 \\
\hline \multirow[t]{3}{*}{ 123I (Nal) (thyroid) } & Activity/mass (MBq/kg) & 5 & 0.06 & 0.22 & 0.11 & 0.13 \\
\hline & Minimum activity (MBq) & 10 & 0.93 & 11.10 & 2.78 & 3.29 \\
\hline & Maximum activity (MBq) & 11 & 3.70 & 18.50 & 8.14 & 9.72 \\
\hline \multirow{3}{*}{$\begin{array}{l}\text { 99mTc-ethylcysteinate dimer or } \\
\text { 99mTc-exametazime }\end{array}$} & Activity/mass (MBq/kg) & 9 & 10.36 & 11.88 & 11.10 & 11.06 \\
\hline & Minimum activity (MBq) & 12 & 44.40 & 370.00 & 185.00 & 160.95 \\
\hline & Maximum activity (MBq) & 12 & 555.00 & $1,110.00$ & 740.00 & 764.67 \\
\hline \multirow[t]{3}{*}{ 99mTc-sestamibi } & Activity/mass (MBq/kg) & 9 & 7.77 & 14.80 & 11.10 & 11.68 \\
\hline & Minimum activity (MBq) & 9 & 37.00 & 518.00 & 148.00 & 197.33 \\
\hline & Maximum activity (MBq) & 10 & 370.00 & $1,110.00$ & 740.00 & 728.90 \\
\hline \multirow[t]{3}{*}{ 99mTc-macroaggregated albumin } & Activity/mass (MBq/kg) & 11 & 1.11 & 2.85 & 1.85 & 1.89 \\
\hline & Minimum activity (MBq) & 12 & 7.40 & 37.00 & 14.80 & 16.95 \\
\hline & Maximum activity (MBq) & 10 & 74.00 & 185.00 & 129.50 & 133.20 \\
\hline \multirow{3}{*}{$\begin{array}{l}\text { 99mTc-Ultratag (Mallinckrodt) } \\
\text { (gastrointestinal bleeding) }\end{array}$} & Activity/mass (MBq/kg) & 10 & 5.18 & 11.10 & 7.40 & 8.04 \\
\hline & Minimum activity (MBq) & 12 & 37.00 & 148.00 & 74.00 & 75.54 \\
\hline & Maximum activity (MBq) & 12 & 370.00 & 925.00 & 610.50 & 595.08 \\
\hline \multirow{3}{*}{$\begin{array}{l}\text { 99mTc-denatured red blood } \\
\text { cells (spleen) }\end{array}$} & Activity/mass (MBq/kg) & 6 & 1.11 & 10.36 & 4.63 & 5.00 \\
\hline & Minimum activity (MBq) & 7 & 18.50 & 74.00 & 37.00 & 42.29 \\
\hline & Maximum activity (MBq) & 7 & 74.00 & 740.00 & 111.00 & 280.14 \\
\hline \multirow{3}{*}{$\begin{array}{l}\text { 99mTc-Ultratag (Mallinckrodt) } \\
\text { (multiple gated acquisitions) }\end{array}$} & Activity/mass (MBq/kg) & 7 & 7.40 & 14.80 & 10.73 & 10.52 \\
\hline & Minimum activity (MBq) & 10 & 37.00 & 259.00 & 92.50 & 115.44 \\
\hline & Maximum activity (MBq) & 10 & 370.00 & 925.00 & 740.00 & 695.60 \\
\hline \multirow[t]{3}{*}{${ }^{67} \mathrm{Ga}$ (inflammatory disease) } & Activity/mass (MBq/kg) & 4 & 1.48 & 2.59 & 1.76 & 1.90 \\
\hline & Minimum activity (MBq) & 4 & 9.25 & 74.00 & 28.49 & 35.06 \\
\hline & Maximum activity (MBq) & 5 & 111.00 & 222.00 & 148.00 & 155.40 \\
\hline \multirow[t]{3}{*}{${ }^{67} \mathrm{Ga}$ (tumor imaging) } & Activity/mass (MBq/kg) & 5 & 1.85 & 5.55 & 4.07 & 3.92 \\
\hline & Minimum activity (MBq) & 5 & 9.25 & 111.00 & 37.00 & 53.65 \\
\hline & Maximum activity (MBq) & 6 & 222.00 & 370.00 & 296.00 & 285.43 \\
\hline \multirow[t]{3}{*}{${ }^{18} \mathrm{~F}-\mathrm{FDG}$} & Activity/mass (MBq/kg) & 12 & 4.44 & 5.55 & 5.18 & 5.18 \\
\hline & Minimum activity (MBq) & 12 & 18.50 & 74.00 & 37.00 & 41.63 \\
\hline & Maximum activity (MBq) & 12 & 370.00 & 555.00 & 407.00 & 425.50 \\
\hline
\end{tabular}


TABLE 2

Mean Differences and Variation between Study Data from 2013 and 2007

\begin{tabular}{|c|c|c|c|c|c|c|c|}
\hline \multirow[b]{2}{*}{ Radiopharmaceutical } & \multirow[b]{2}{*}{ Parameter } & \multicolumn{3}{|c|}{ Mean difference, 2013-2007 } & \multicolumn{2}{|c|}{$\begin{array}{l}95 \% \text { confidence interval } \\
\text { of mean in... }\end{array}$} & \multirow{2}{*}{$\begin{array}{l}\text { Factor of variation in } \\
2007 \text { and } 2013\end{array}$} \\
\hline & & Minimum & Maximum & Mean & 2007 & 2013 & \\
\hline \multirow[t]{3}{*}{ 99mTc-dimercaptosuccinic acid } & Activity/mass (MBq/kg) & -1.85 & 0.74 & -0.48 & $1.50,3.20$ & $1.64,2.17$ & $3.3,2.3$ \\
\hline & Minimum activity (MBq) & -24.05 & 18.50 & -5.55 & $13.46,39.35$ & $13.71,28.98$ & $13.3,9.0$ \\
\hline & Maximum activity (MBq) & -74.00 & 0.00 & -20.56 & $117.18,185.54$ & $96.61,152.30$ & $3.0,2.5$ \\
\hline \multirow[t]{3}{*}{ 99mTc-mercaptoacetyltriglycine } & Activity/mass (MBq/kg) & -6.66 & 2.96 & -2.07 & $2.93,8.45$ & $2.38,4.72$ & $5.6,5.0$ \\
\hline & Minimum activity (MBq) & -74.00 & 18.50 & -6.22 & $28.18,79.74$ & $26.21,69.31$ & $8.0,8.2$ \\
\hline & Maximum activity (MBq) & -222.00 & 0.00 & -112.55 & $215.94,341.91$ & $117.75,243.00$ & $3.3,6.7$ \\
\hline \multirow[t]{3}{*}{ 99mTc-methylene diphosphate } & Activity/mass (MBq/kg) & -4.07 & 0.00 & -1.85 & $9.50,12.24$ & $8.49,9.40$ & $1.8,1.3$ \\
\hline & Minimum activity (MBq) & -148.00 & 0.00 & -41.00 & $65.84,133.96$ & $45.21,85.52$ & $8.3,3.0$ \\
\hline & Maximum activity (MBq) & -370.00 & 74.00 & -70.63 & $757.22,882.17$ & $666.71,826.75$ & $1.4,1.7$ \\
\hline \multirow[t]{3}{*}{ 99mTc-diisopropyl iminodiacetic acid } & Activity/mass (MBq/kg) & -1.85 & -0.59 & -1.22 & $2.28,3.65$ & $1.52,2.29$ & $2.0,3.8$ \\
\hline & Minimum activity (MBq) & -55.50 & 0.00 & -4.26 & $24.74,47.61$ & $22.44,41.37$ & $5.0,5.0$ \\
\hline & Maximum activity (MBq) & -185.00 & 74.00 & -34.23 & $151.53,249.78$ & $134.23,201.24$ & $4.0,5.0$ \\
\hline \multirow[t]{3}{*}{ 123/-metaiodobenzylguanidine } & Activity/mass (MBq/kg) & -2.22 & 1.85 & -0.11 & $4.92,6.39$ & $4.97,6.13$ & $1.4,1.7$ \\
\hline & Minimum activity (MBq) & -85.10 & 0.00 & -22.87 & $36.99,114.37$ & $34.06,68.93$ & $5.0,3.0$ \\
\hline & Maximum activity (MBq) & 0.00 & 0.00 & 0.00 & $345.17,374.91$ & $345.17,374.91$ & $1.3,1.3$ \\
\hline \multirow[t]{3}{*}{ 99mTc-NaTcO 4 (Meckel diverticulum) } & Activity/mass (MBq/kg) & -4.07 & 0.00 & -1.85 & $3.04,5.88$ & $1.95,3.19$ & $3.6,2.3$ \\
\hline & Minimum activity (MBq) & -74.00 & 74.00 & -18.61 & $23.04,75.50$ & $12.49,55.53$ & $20.0,15.0$ \\
\hline & Maximum activity (MBq) & -185.00 & 0.00 & -66.60 & $263.09,433.75$ & $212.35,460.38$ & $5.0,6.7$ \\
\hline \multirow[t]{3}{*}{ 123I (Nal) (thyroid) } & Activity/mass (MBq/kg) & 0.00 & 0.00 & 0.00 & $0.01,0.23$ & $0.05,0.21$ & $4.0,4.0$ \\
\hline & Minimum activity (MBq) & -5.92 & 3.70 & -0.85 & $1.41,6.11$ & $1.04,5.55$ & $20.0,12.0$ \\
\hline & Maximum activity (MBq) & -9.99 & 11.10 & 0.85 & $5.90,13.01$ & $6.02,13.43$ & $5.4,5.0$ \\
\hline \multirow{3}{*}{$\begin{array}{l}\text { 99mTc-ethylcysteinate dimer or } \\
\text { 99mTc-exametazime }\end{array}$} & Activity/mass (MBq/kg) & 0.00 & 9.25 & 2.22 & $6.55,15.07$ & $10.76,11.37$ & $8.5,1.1$ \\
\hline & Minimum activity (MBq) & -185.00 & 166.50 & -3.70 & $100.47,249.35$ & $107.26,214.64$ & $20.0,8.3$ \\
\hline & Maximum activity (MBq) & -370.00 & 555.00 & -50.47 & $654.83,967.00$ & $678.24,851.09$ & $3.0,2.0$ \\
\hline \multirow[t]{3}{*}{ 99mTc-sestamibi } & Activity/mass (MBq/kg) & -7.40 & 8.07 & 0.44 & $8.38,15.55$ & $9.95,13.42$ & $3.2,1.9$ \\
\hline & Minimum activity (MBq) & -333.00 & 37.00 & -32.38 & $99.96,321.84$ & $76.67,318.00$ & $14.0,14.0$ \\
\hline & Maximum activity (MBq) & -555.00 & 444.00 & -55.50 & $668.64,916.19$ & $557.34,900.46$ & $3.0,3.0$ \\
\hline \multirow[t]{3}{*}{ 99mTc-macroaggregated albumin } & Activity/mass (MBq/kg) & -2.04 & 0.74 & -0.41 & $1.17,3.45$ & $1.48,2.31$ & $4.4,2.6$ \\
\hline & Minimum activity (MBq) & -22.20 & 3.70 & -4.44 & $14.83,27.96$ & $12.54,21.38$ & $5.0,5.0$ \\
\hline & Maximum activity (MBq) & -74.00 & 0.00 & -11.84 & $120.75,167.23$ & $107.63,158.77$ & $2.0,2.5$ \\
\hline \multirow{3}{*}{$\begin{array}{l}\text { 99mTc-Ultratag (Mallinckrodt) } \\
\text { (gastrointestinal bleeding) }\end{array}$} & Activity/mass (MBq/kg) & -1.85 & 3.70 & 0.30 & $4.92,10.92$ & $6.54,9.55$ & $3.0,2.1$ \\
\hline & Minimum activity (MBq) & -74.00 & 74.00 & -6.18 & $48.99,107.23$ & $55.21,95.88$ & $4.0,4.0$ \\
\hline & Maximum activity (MBq) & -370.00 & 185.00 & -55.50 & $478.37,752.72$ & $473.36,716.81$ & $4.0,2.5$ \\
\hline \multirow{3}{*}{$\begin{array}{l}\text { 99mTc-denatured red blood cells } \\
\text { (spleen) }\end{array}$} & Activity/mass (MBq/kg) & -1.48 & 0.00 & -0.74 & $-2.48,6.92$ & $0.92,9.07$ & $1.4,9.3$ \\
\hline & Minimum activity (MBq) & 0.00 & 37.00 & 12.32 & $11.51,68.66$ & $20.84,63.73$ & $5.0,4.0$ \\
\hline & Maximum activity (MBq) & -111.00 & 592.00 & 120.25 & $-56.99,488.65$ & $10.08,550.21$ & $10.0,10.0$ \\
\hline \multirow{3}{*}{$\begin{array}{l}\text { 99mTc-Ultratag (Mallinckrodt) } \\
\text { (multiple gated acquisitions) }\end{array}$} & Activity/mass (MBq/kg) & 0.00 & 0.00 & 0.00 & $5.87,13.52$ & $8.30,12.74$ & $2.0,2.0$ \\
\hline & Minimum activity (MBq) & -111.00 & 18.50 & -16.65 & $63.61,200.57$ & $63.92,166.96$ & $8.3,7.0$ \\
\hline & Maximum activity (MBq) & -370.00 & 185.00 & -37.00 & $653.25,813.29$ & $591.36,799.84$ & $1.7,2.5$ \\
\hline \multirow[t]{3}{*}{${ }^{67} \mathrm{Ga}$ (inflammatory disease) } & Activity/mass (MBq/kg) & -0.37 & 0.00 & -0.11 & $1.35,2.45$ & $1.05,2.74$ & $1.8,1.8$ \\
\hline & Minimum activity (MBq) & -9.25 & 0.00 & -4.63 & $-10.88,80.25$ & $-10.08,80.19$ & $8.0,8.0$ \\
\hline & Maximum activity (MBq) & -74.00 & 111.00 & 9.25 & $115.99,192.34$ & $95.50,215.30$ & $1.7,2.0$ \\
\hline \multirow[t]{3}{*}{${ }^{67} \mathrm{Ga}$ (tumor imaging) } & Activity/mass (MBq/kg) & -0.07 & 0.00 & -0.04 & $2.76,5.04$ & $2.01,5.83$ & $1.8,3.0$ \\
\hline & Minimum activity (MBq) & -27.75 & 74.00 & 9.25 & $19.25,62.89$ & $4.65,102.65$ & $12.0,12.0$ \\
\hline & Maximum activity (MBq) & -74.00 & 74.00 & -21.14 & $271.79,354.12$ & $238.20,332.66$ & $1.7,1.7$ \\
\hline${ }^{18} \mathrm{~F}-\mathrm{FDG}$ & Activity/mass (MBq/kg) & -1.85 & 0.00 & -0.48 & $4.77,6.58$ & $5.01,5.35$ & $1.4,1.3$ \\
\hline & Minimum activity (MBq) & 0.00 & 0.00 & 0.00 & $22.47,70.03$ & $31.45,51.81$ & $4.0,4.0$ \\
\hline & Maximum activity (MBq) & -185.00 & 185.00 & 0.00 & $368.40,491.85$ & $381.24,469.77$ & $1.5,1.5$ \\
\hline
\end{tabular}


TABLE 3

Percentage of Institutions Within $\pm 20 \%$ of North American Consensus Guidelines for Administered Radiopharmaceutical Activities in Children and Adolescents

\begin{tabular}{|c|c|c|c|c|c|c|}
\hline \multirow[b]{2}{*}{ Radiopharmaceutical } & \multicolumn{3}{|c|}{2007 administered activity } & \multicolumn{3}{|c|}{2013 administered activity } \\
\hline & $\begin{array}{l}\text { Based on } \\
\text { weight only }\end{array}$ & Minimum & Maximum & $\begin{array}{l}\text { Based on } \\
\text { weight only }\end{array}$ & Minimum & Maximum \\
\hline${ }^{18} \mathrm{~F}-\mathrm{FDG}$ & $83.3 \%(5 / 6)$ & $50.0 \%(3 / 6)$ & & $91.7 \%(11 / 12)$ & $75.0 \%(9 / 12)$ & \\
\hline 99mTc-methylene diphosphate & $0.0 \%(0 / 8)$ & $15.4 \%(2 / 13)$ & & $81.8 \%(9 / 11)$ & $50.0 \%(6 / 12)$ & \\
\hline 123|-metaiodobenzylguanidine & $85.7 \%(6 / 7)$ & $54.6 \%(6 / 11)$ & $84.6 \%(11 / 13)$ & $75.0 \%(9 / 12)$ & $75.0 \%(9 / 12)$ & $84.6 \%(11 / 13)$ \\
\hline 99mTc-diisopropyl iminodiacetic acid & $14.3 \%(1 / 7)$ & $23.1 \%(3 / 13)$ & & $70.0 \%(7 / 10)$ & $30.8 \%(4 / 13)$ & \\
\hline 99mTc-dimercaptosuccinic acid & $25.0 \%(2 / 8)$ & $0.0 \%(0 / 11)$ & & $66.7 \%(8 / 12)$ & $0.0 \%(0 / 13)$ & \\
\hline 99mTc-NaTcO 4 (for Meckel diverticulum) & $0.0 \%(0 / 7)$ & $8.3 \%(1 / 12)$ & & $45.5 \%(5 / 11)$ & $38.5 \%(5 / 13)$ & \\
\hline 99mTc-mercaptoacetyltriglycine & $12.5 \%(1 / 8)$ & $41.7 \%(5 / 12)$ & $0.0 \%(0 / 13)$ & $30.0 \%(3 / 10)$ & $75.0 \%(9 / 12)$ & $50.0 \%(6 / 12)$ \\
\hline 99mTc-macroaggregated albumin & $14.3 \%(1 / 7)$ & $0.0 \%(0 / 12)$ & & $27.3 \%(3 / 11)$ & $58.3 \%(7 / 12)$ & \\
\hline
\end{tabular}

(EANM). In addition, the package insert of commercially available radiopharmaceuticals provides guidance on the usual adult administered activities. However, very little information is available with regard to pediatric nuclear medicine. Thus, many pediatric imaging centers have developed their own approaches for children.

The survey that our group administered in 2007 indicated that there was a wide variation in the practice of pediatric nuclear medicine with regard to the determination of administered activities even among dedicated pediatric institutions. The publication of the results of the 2007 survey engendered a discussion within the North American pediatric nuclear medicine community that ultimately led to the development and publication of the North American consensus guidelines for administered radiopharmaceutical activities in children and adolescents (6). In addition, the "Image Gently" campaign with support from the SNMMI undertook an extensive public relations campaign entitled "Go with the Guidelines," which sought to deliver a poster of the guidelines to every nuclear medicine clinic in the United States and Canada. The poster was also published in several major nuclear medicine and imaging journals, including The Journal of Nuclear Medicine, Journal of Nuclear Medicine Technology, Radiology, and Pediatric Radiology. The EANM also established a pediatric dose project (PEDDOSE) around this same time that led to the development and distribution of the EANM pediatric dosage card (8). Since the EANM dosage card was based on a different approach from the North American guidelines, it led to relatively different recommended values in several instances. More recently, the EANM and the North American group collaborated on harmonizing the two, leading to the publication of the 2014 version of both the EANM dosage card and the North American guidelines $(9,10)$. A pediatric activity tool that provides recommended values from both sets of guidelines is currently available on the SNMMI website (www.snmmi.org/pedactivitytool) (11).

In general, the values reported in the 2013 survey are similar to or lower than those reported in 2007, particularly for those procedures addressed in the 2010 North American guidelines. In some instances, the reported administered activities were actually higher in 2013 than in 2007, but none of these procedures were addressed in the North American guidelines and thus no guidance was provided for reduction of administered activity. Some of these procedures, such as ${ }^{67} \mathrm{Ga}$, are no longer commonly practiced in pediatric nuclear medicine, in part because of the relatively high radiation exposure with this agent. In addition, the "Image Gently" group is now considering recommended levels for radiopharmaceuticals not yet addressed by the North American guidelines. This effort should soon lead to an addendum to the guidelines.

We also looked at the range of responses by considering a factor of variability given by the ratio of the highest value to the lowest value reported by a certain institution. Across the 16 procedures, the variation in the administered activity per body mass and the minimum activity was reduced by $9.7 \%$ and $24 \%$, respectively. The reduction in variability in the minimum activity is most encouraging because this reduction affects our smallest patients, who are considered to be our most vulnerable. The factor of variability for the maximum activity increased. However, in general, this was the result of some institutions reducing their maximum activities while others retained their previous values, leading to an overall reduction in this value.

Although the results of this follow-up survey are encouraging from a dose optimization point of view, not all these institutions were uniformly compliant with the North American guidelines. Even though all the institutions reported that they were familiar with "Image Gently" and the North American guidelines, only 10 of the 13 institutions indicated that they modified their administered activities according to the guidelines. As a result, for $33 \%$ of the 24 parameters (minimum and maximum administered activities and the administered activity/mass) associated with the 8 procedures addressed in the guidelines, more than $50 \%$ of the institutions were not compliant, despite the fact that many of the groups involved in the development of the North American guidelines were from these same institutions. However, there may have been instances in which the value at a particular institution was lower than that recommended by the guidelines and thus the institution did not feel compelled to make such an adjustment. In addition, some institutions chose to sometimes retain higher administered activities, possibly because the specific patient population may differ from that of the other institutions. This choice could also be related to differences in image processing or reconstruction, imaging equipment such as collimation, and practitioners' preference.

\section{CONCLUSION}

In general, the 13 pediatric institutions that were initially surveyed in 2007 have reduced their administered activities in children, particularly for those procedures that were addressed by the 2010 North American 
guidelines. In addition, the variability in activity per body mass and in minimum activity was substantially reduced. The variability in maximum activity was increased, but mostly because some sites reduced their limits while others maintained their previous values. Ten of the 13 institutions reported that they adjusted their scheme for administered activities according to the North American guidelines. Thus, the publication of these guidelines and the associated public relations program appear to have had a positive effect on both dose optimization and procedure standardization in pediatric nuclear medicine. However, more assertive communication regarding the value of the North American guidelines may have led to a higher level of compliance. As more data are gathered and practices are updated and refined, guidelines on administered activities in children will likely continue to evolve.

\section{DISCLOSURE}

The costs of publication of this article were defrayed in part by the payment of page charges. Therefore, and solely to indicate this fact, this article is hereby marked "advertisement" in accordance with 18 USC section 1734 . No potential conflict of interest relevant to this article was reported.

\section{ACKNOWLEDGMENTS}

We thank the following institutions for participating in the survey: Children's Hospital of Philadelphia, Children's Hospital of Pittsburgh, Ann and Robert H. Lurie Children's Memorial Hospital in Chicago, Cincinnati Children's Hospital, Children's National Medical Center in Washington, DC, Children's Hospital of Seattle, the Hospital for Sick Children in Toronto, British Columbia Children's Hospital in Vancouver, Children's Hospital Los Angeles, St. Jude
Children's Research Hospital, Children's Healthcare of Atlanta at Scottish Rite, and Miami Children's Hospital. Without their cooperation, this investigation would not have been possible.

\section{REFERENCES}

1. Treves ST. Pediatric Nuclear Medicine and Molecular Imaging. 4th ed. New York, NY: Springer; 2014.

2. Committee to Assess Health Risks from Exposure to Low Levels of Ionizing Radiation, National Research Council. Health Risks from Exposure to Low Levels of Ionizing Radiation: BEIR VII Phase 2. Washington, DC: National Research Council of the National Academies; 2006.

3. Fahey FH, Treves ST, Adelstein SJ. Minimizing and communicating risk in pediatric nuclear medicine. J Nucl Med. 2011;52:1240-1251.

4. Treves ST, Davis RT, Fahey FH. Administered radiopharmaceutical doses in children: a survey of 13 pediatric hospitals in North America. J Nucl Med. 2008;49: 1024-1027.

5. Goske MJ, Applegate KE, Boylan J. Image Gently(SM): a national education and communication campaign in radiology using the science of social marketing. J Am Coll Radiol. 2008;5:1200-1205.

6. Gelfand MJ, Parisi MT, Treves ST. Pediatric radiopharmaceutical administered doses: 2010 North American consensus guidelines. J Nucl Med. 2011;52:318322.

7. Title 10 of the Code of Federal Regulations, part 35, section 35.3045: report and notification of a medical event. U.S. Nuclear Regulatory Commission website. http://www.nrc.gov/reading-rm/doc-collections/cfr/part035/part035-3045.html. Accessed April 24, 2015.

8. Lassmann M, Biassoni L, Monsieurs M, et al. The new EANM paediatric dosage card. Eur J Nucl Med Mol Imaging. 2007;34:796-798.

9. Lassmann M, Treves ST. Pediatric radiopharmaceutical administration: harmonization of the 2007 EANM paediatric dosage card (version 1.5.2008) and the 2010 North American consensus guideline [comment]. Eur J Nucl Med Mol Imaging. 2014;41:1636.

10. Treves ST, Lassmann M. International guidelines for pediatric radiopharmaceutical administered activities. J Nucl Med. 2014;55:869-870.

11. Pediatric injected activity tool. Society of Nuclear Medicine and Molecular Imaging website. www.snmmi.org/pedactivitytool. Accessed April 17, 2015.

\section{Erratum}

In Figure 2 of the article "Gleason Score at Diagnosis Predicts the Rate of Detection of ${ }^{18}$ F-Choline PET/CT Performed When Biochemical Evidence Indicates Recurrence of Prostate Cancer: Experience with 1,000 Patients," by Cimitan et al. ( $\mathrm{Nucl} \mathrm{Med.} \mathrm{2015;56:209-215),} \mathrm{the} \mathrm{reported} \mathrm{sensitivities} \mathrm{for} \mathrm{serum} \mathrm{prostate-specific} \mathrm{antigen} \mathrm{are}$ incorrect. The correct sensitivities are $58.4 \%, 79.5 \%, 84.2 \%$, and $89.8 \%$ for prostate-specific antigen levels of 1.00 , $1.50,2.00$, and $5.00 \mathrm{ng} / \mathrm{mL}$, respectively. The authors regret the error. 